Fraunhofer

Institute

Systems and

Innovation Research

Fraunhofer ISI Discussion Papers Innovation Systems and Policy Analysis, No. 16

ISSN 1612-1430

Karlsruhe, September 2008

\title{
Gender-Specific Patterns in Patenting and Publishing
}

\author{
Rainer Frietsch $^{\mathrm{a} *}$, Inna Haller ${ }^{\mathrm{b}}$, Melanie Vrohlings ${ }^{\mathrm{b}}$ and Hariolf Grupp ${ }^{\mathrm{a}, \mathrm{b}}$ \\ ${ }^{a}$ Fraunhofer Institute for Systems and Innovation Research (Fraunhofer ISI) \\ ${ }^{b}$ IWW Institut für Wirtschaftspolitik und Wirtschaftsforschung, \\ University of Karlsruhe (TH)
}

* Corresponding author: phone: +49 721 6809-197, fax: +49 721 6809-260, e-mail: rainer.frietsch@isi.fraunhofer.de 


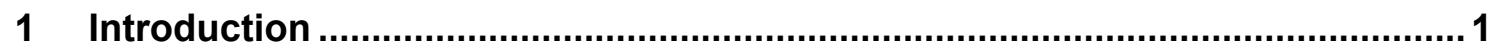

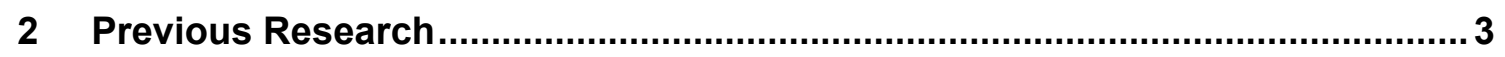

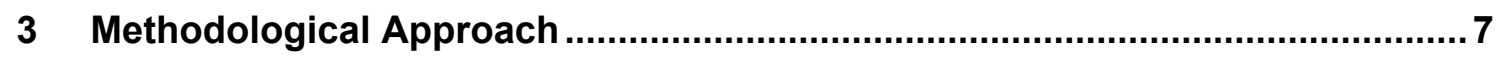

4 Data

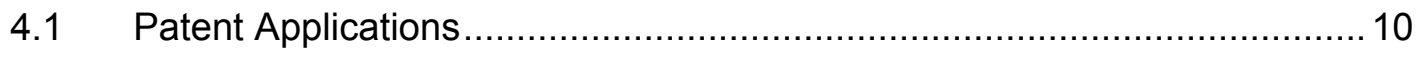

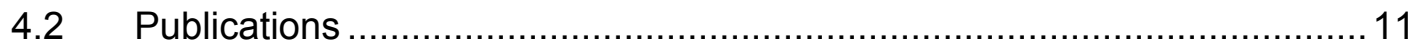

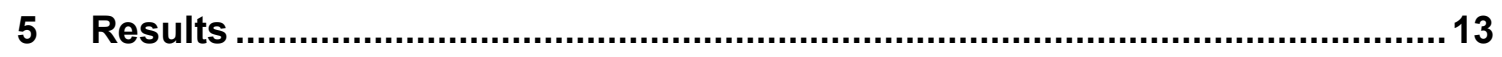

$5.1 \quad$ Patent Applications ………………

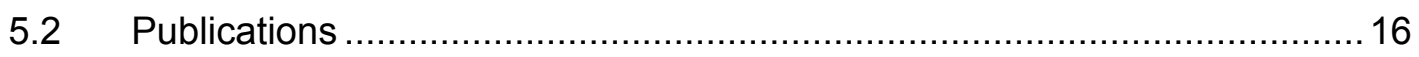

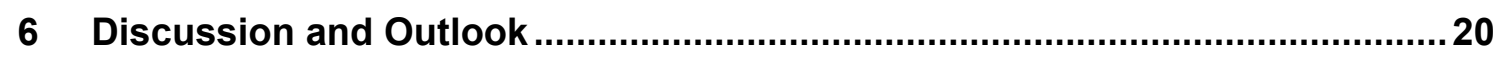

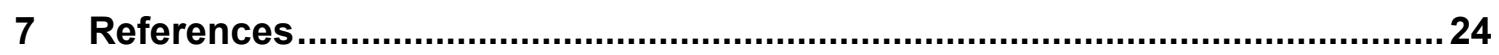

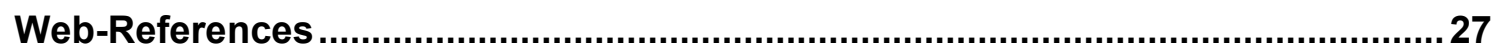

\section{Tables}

Table 1: Distribution of scientific areas in the extracted database and in the complete Scopus database ............................................................... 12

Table 2: Women's 'contribution' (patent applications), 1991-2005 ……..................13

Table 3: Shares of women's contribution by technological fields, 2003-2005 ..........14

Table 4: Shares of women's 'contribution' (publications), 1996-2005....................... 17

Table 5: Shares of women's contribution by scientific areas, 2005 ........................19

\section{Figures}

Figure 1: Total shares of women's contribution to technology output in five technology areas, 1991-2005.

Figure 2: Total shares of women's contribution to scientific output, 19962005

Figure 3: Shares of women's contribution (publications) 2005 and expenditure on pre-primary education as a share of GDP 2004

Figure 4: Shares of women's contribution (patents) 2003-2005 and remuneration of researchers 2006 


\begin{abstract}
Measuring the output of men and women in science and technology has previously been mostly restricted to case studies or small-scale surveys. Based on an analysis of patent and publication databases, this paper applies a methodology to systematically assign the gender to the names of inventors and authors. The method is applied to 14 countries. The results of this investigation reveal substantial differences across countries in terms of women's relative contribution 1 to science and technology, with the central European countries of Germany, Austria and Switzerland all ranking comparatively low in this respect. We also examine trends over time, showing that the data on women's share of publications - unlike the results for patents - hardly increase over time for the already better-performing nations.
\end{abstract}

\title{
Keywords
}

Measurement, R\&D output, gender equality, gender-specific patenting, gender-specific publishing

1 We should emphasize that use of the term "contribution" is not intended to imply any appraisal of the research activities involved. 
Globalisation, advanced technologies, demographic change and migration strongly shape modern societies. To sustain their competitiveness, an optimised and effective usage of human capital is essential: education and qualifications have therefore become among the most crucial factors in recent years. In times of shortcomings in the labour market, with increasing demand for highly qualified personnel but a shrinking supply, not least because of the demographic trends in most industrial countries, an efficient and sophisticated use of investments in human capital is essential. In particular, facilitating higher qualifications among women and their broader participation in the labour market are amongst the most important means to overcome these shortcomings and trends.

Although in recent years some structural changes in this direction are apparent, further improvement is nevertheless desirable. Statistics on the gender-specific distribution of qualifications reveal that, at least for the EU-25 countries (European Commission 2006 b, p. 55), more than half of the graduates (59\%) from European universities in 2003 were women. In the same year, women completed $43 \%$ of the doctoral theses that were examined and $32 \%$ of the habilitations. Yet there were only $15 \%$ female professors employed at universities. Compared to previous years, all these percentages had increased, but one rule still holds true: the higher the academic degree or position, the lower the share accounted for by women. These statistics reveal the well-known phenomenon of the 'leaky pipeline', by which the proportion of women tends to decrease as they approach higher steps of the ladder (Commission of the European Communities 2003). Figures for the United States likewise show the disappearance of women at each successive academic career stage (United States Government Accountability Office 2005). This finding can be confirmed in most OECD countries (OECD Employment 2006).

More effective use of female human capital is potentially one of the best ways to enhance the competitiveness and quality of the knowledge-based society. The problem confronting most technologically advanced societies is due not only to the absence of suitably qualified employees but also to an allocation problem with regard to female human resources. Recognising the resulting need for change is the first step, along with understanding the factors that constrain women from pursuing a scientific career. From an individual point of view, women often find themselves in the position of having

2 Part of this work was funded by the Federal Ministry of Education and Research (BMBF) of Germany and was published in the annual report on the "Technological Competitiveness of Germany". 
to choose between family and career. At the level of society, there is a broader 'economic dilemma' using the scientific and economic potential of women to better effect may, at the same time, lead to fewer offspring, something that may be equally detrimental to the prosperity of society; for, as various studies have shown, better educated women on average tend to have fewer children (Duschek \& Wirth 2005; Holz 2003; Wirth \& Dümmler 2005).

Political efforts have been made that aim to secure the more efficient utilisation of highly qualified human capital, for example by encouraging women to study and work in the area of science and research, or by changing the framework conditions to help individuals balance their family and career. Some studies that have analysed the incomes of men and women have found significant disparities (Ammermüller, Weber 2005; Ehrenberg, Smith 2003; Machin, Puhani 2003). The 'Report on Equality between Women and Men, 2006', published by the European Commission, refers to the principle of equal gender treatment, which should have been accomplished in all Member States by October $5^{\text {th }}, 2005$ (European Commission, 2006a, p. 8). In order to acquire better information on developments in this area, the European Commission has suggested creating a European Institute for Gender Equality (European Commission, 2005). Currently, the European Council and the European Parliament are deliberating on this proposal. Awareness of the nature and scale of the problem is obviously important for the draft European law regarding gender mainstreaming (European Union: Gender Equality).

The preceding discussion highlights the fact that most of the analyses in this area have focused on the input side of human capital and the challenging aspects of demography and knowledge intensification. Particularly in research and development (R\&D) processes and projects, ensuring adequate inputs of human (and financial) capital is clearly of crucial importance. However, only a relatively few attempts have been made to measure the R\&D outputs of women, which is the focus of this study. Most often these attempts have used surveys or case studies, while few have been able to make use of large-scale quantitative data. In this paper, we examine the extent to which women contribute to the outputs from science and technology. A range of countries 3 are considered in order to allow direct comparisons. The immediate objective of this paper is to explore how far the chosen methodological approach can help us understand the nature and the causes of the problem.

3 Australia (AUS), Austria (AUT), Belgium (BEL), Denmark (DEN), France (FRA), Germany (GER), Ireland (IRL), Italy (ITA), New Zealand (NZL), Spain (ESP), Sweden (SWE), Switzerland (SUI), the United Kingdom (GBR) and the USA (USA). 
The paper is organised as follows: in the next section, some earlier work in this area is surveyed. The methodological approach is presented in section three. Existing patent and publication databases are described and we outline how the required information about the scientific contribution of women is obtained by combining these databases with country-specific lists of first names 4 . Some details on patent application and publication data are given in section four. In section five, the results are presented and discussed. Finally, section six concludes that there are significant differences in women's output in technology and science between the investigated countries. Some explanations for this finding are offered.

\section{Previous Research}

Various studies have dealt with questions of gender mainstreaming and with the relative chances of men and women attaining senior positions in companies or universities, studying certain subjects, being able to combine family and career, or being successful as an entrepreneur. Some of these studies have attempted to make comparisons across countries. However, since structures, laws and regulations are all important in this context, most studies have tended to focus on individual countries. Some of the authors of these studies have used qualitative data obtained from interviews or observations; others have used quantitative data from their own surveys or small-scale exercises based on the matching of data.

Eurostat (Frank 2006) recently published a report analysing the share of R\&D personnel in Europe and other regions, including a breakdown by gender. Amongst other results, they found that Latvia $(53.1 \%)$ and Lithuania $(48.3 \%)$ had the highest proportion of female researchers in 2003 , followed closely by Bulgaria (46.6\%). In contrast, Germany $(19.2 \%)$, Luxemburg $(17.4 \%)$ and Japan (11.6\%) were the countries with the lowest proportion of female researchers. In another study, the European Commission took a closer look at the situation of women in research and development, and in science and technology fields. One of their findings was that across the EU only $29 \%$ of researchers are female. Moreover, they found that "in higher education, only $15 \%$ of those at the highest academic grade (grade A) are women" (European Commission, 2006b, p. 8).

4 This list is derived from Naldi et al. (2002a; 2002b); it was extended and developed by Fraunhofer ISI and by the Institute for Economic Policy Research (IWW) at the University of Karlsruhe. 
Xie and Shauman $(1998,2003)$ have analysed the representation of women in science and engineering in the United States. Their 1998 study yielded two key findings: first, the gender gap in terms of research productivity declined over the period between 1969 and 1993. Second, differences regarding the research productivity of men and women can largely be explained in terms of differences in personal characteristics, structural positions and marital status. The 2003 study considered education in science and engineering, distinguishing four categories: biological science, engineering, mathematics and computer science, and physical science. Xie and Shauman (2003) emphasize differences in the academic structures in which female and male scientists are located. However, if the differences in the distribution of resources such as space, equipment, and time are taken into account, the productivity gap between men and women seems to be negligible.

Long (2001) also reports changes in the science and engineering careers of women between 1975 and 1995. Data for this analysis were obtained from two National Science Foundation databases, the Survey of Earned Doctorates for New PhDs and the Survey of Doctoral Recipients for the science \& engineering doctoral workforce. The study's most fundamental finding is that, while females are earning an increasing proportion of the doctorates in science and engineering, they are not participating in the S\&E workforce at commensurate levels.

Ding at al. (2006) analysed longitudinal data on academic careers and conducted interviews with faculty members to determine the scope and causes of the gender gap in patenting among life scientists. The study evaluated a random sample of 4227 life scientists over a 30 year period. It revealed that female academic scientists patent at about $40 \%$ of the rate of men. However, Ding at al. (2006) found that the gender gap has decreased over time, although it still remains large.

In earlier decades, Zuckerman and Cole (1975) and Cole and Zuckerman (1984) found evidence that women publish less than men and that the quality of their publications is lower. More recently, Penas and Willet (2006) also found evidence for differences in the productivity of men and women, but not for the quality of their work, at least as measured by citation counts. Zuckerman and Cole offered several explanations for this puzzle, one being that women choose institutional settings where publishing is not expected or encouraged. Furthermore, marriage and motherhood may keep women away from publishing, as may institutional discrimination, these providing two further possible explanations. None of these explanations is completely satisfactory, however, and the conclusion is that structures and framework conditions matter and these have to be carefully monitored and controlled when differences in the productivity of men and women are discussed. 
More recent empirical evidence suggests that, even though women's productivity is still below that of men, children and motherhood are not apparently able to account for this difference (Fox 2005; Stack 2004). This contradicts Long (1990), who previously found some evidence that motherhood has a negative impact on networking activities in the early years of the career and thereby an indirect negative effect on productivity. A relatively new and interesting perspective analyses the degree of specialisation of individuals within research areas, arguing that women lose out in terms of productivity by specialising less clearly in their topic on average than men (Leahey 2006).

Differences in the productivity of female researchers have also been found by Prpic (2002). Based on Croatian data, she claims that differences in the productivity of men and women have even been increasing in recent years. The qualificational background of individuals is not able to explain the unequal outcomes, but the exact position within the research institution and also international networking do account for at least some of the differences.

Bunker Whittington (2006), and Bunker Whittington and Smith-Doerr (2005) have been able to link the inputs and outputs of women in the research process. Based on a survey, they find that the sector of the institution - whether it is in industry or academia has a significant impact on the outcome of this process. However, they conclude that the difference in the propensity to publish or patent between men and women in industry compared with those in academia has its origin in different opportunity structures. Women - actively or passively - do not have the opportunities to publish to the same extent as their male counterparts, for example because they are not encouraged to do so or because they choose less exploitable research areas. The latter is similar to the explanation offered by Zuckerman and Cole (1975). Concerning patenting, the most interesting finding is that women entered the patenting system file at similar rates to men (Bunker-Whittington 2006: 29) - at least in the academic sector. This latter result is also found for the publications of Spanish researchers, when their position is controlled for (Mauléon, Bordons 2006). However, in a two-stage model BunkerWhittington and Smith-Doerr (2006) were able to show differences between the academic and commercial sector, and the difference in the number of patents filed is persistent, even if the level of involvement - in terms of patenting vs. not patenting at all is controlled for.

Moody (2004) and Moody and Light (2007) focus on collaboration networks in sociology, with Moody 2004 looking in particular at co-authorship. Amongst other things, these authors estimate the effects of gender on the collaboration and the position in a network by linking first names to the gender distribution of first names in the Census. Moody suggests that co-authorship networks differ by gender: women are strongly in- 
tegrated into the overall network core of the discipline whereas males are less likely to be a co-author. Naldi et al. $(2002 ; 2004)$ use patents and publications to analyse the contribution of women to scientific and technological development. They created a database of 8291 first names (differentiated by six countries or languages). 5 After applying their first-name database (FNDB) to the patent application and publication data for the year 1998, they show that women are rather more heavily involved in producing publications than patents. If we compare countries, the one with the highest percentage of female inventors is Spain, followed by France and Italy, while in the scientific arena, Italian women have the highest share, followed by Spain and France. A study by Burkhardt and Greif (2001) focuses on the extent to which women in Germany contribute to the technological development as reflected in patent data. Amongst other things, they conclude that the proportion of patent applications by women has increased by about $60 \%$ between 1995 and 1999, but the absolute value (3.5-7.5\%) is still relatively small.

To sum up, there has been a series of studies that deal with the issue of the participation and productivity of females in science and technology. The survey of the empirical literature presented here shows one clear finding: the proportion of women decreases with an increasing level of education and seniority. Furthermore, women are - for one reason or another - less active in publishing and patenting than men. However, there is only relatively little evidence based on cross-country comparisons; most of the results in this area are based on case studies or restricted surveys. The application of largescale databases in gender research in order to draw international comparisons over long time periods remains a challenging task. In this study, we attempted to address this gap by electronically combining large-scale and cross-country databases on patent applications and publications with the first-name database (FNDB) originally developed by Naldi et al. (2002; 2004). In this way, we have been able to extend the range of scientific and innovation indicators that can be subject to a rigorous analysis in terms of the gender dimension.

5 United Kingdom, France, Germany, Italy, Spain and Sweden. 


\section{$3 \quad$ Methodological Approach6}

As part of the mechanism for the protection of intellectual property, patents play a specific and crucial role, not least because the formal requirements for patent applications are very strict. From an analytical perspective, patents can be viewed as an indicator of the codified knowledge of enterprises, and, in a wider perspective, of countries (Frietsch and Schmoch 2006; Schmoch and Hinze 2004). This study uses patent applications rather than granted patents, partly because the former are published earlier and partly because they better reflect the technological competitiveness of an invention (whereas the latter reflect the economic competitiveness and market strength of the inventor as well as the market attractiveness of the invention). It can be assumed that patent applications are preceded by often quite large investments in the research and development process (Grupp, 1998, 145-147; Kash \& Kingston, 2001). Therefore, patents can be regarded as an output indicator (or a success indicator) of research and development (R\&D) processes (Freeman, 1982, p. 8). On the other hand, most technological inventions are used to help develop new or improved products or processes, which are then made available on national or international markets. Thus, patents can also be interpreted as input or throughput indicators with regard to the future market activities of enterprises, sectors or countries. In this respect, they may act as early signals of future competitiveness.

European patent applications are used in this study, since, at this trans-national office, the 'home advantage' of different countries is not as large as in most national offices. 7 Furthermore, European filings involve the same methodological and administrative procedures and are therefore easier to compare across countries than filings at several national offices, each with its own national idiosyncrasies. As a data source to establish our offline database for an analysis of gender-specific contributions to technological

6 Further details on the methodological approach are given in a paper by the authors on "New Possibilities for Measuring the Gender Specific S\&T Output" (in preparation).

7 It is obvious, for example, that German applicants and inventors account for much higher shares of patents in Germany than in France, and conversely that French applicants and inventors have a much lower share in Germany than in France - even after a correction has been made for size differences. This effect is known as the 'home advantage'. To compensate for this, the concept of Triadic patents (with applications in Japan, the US and Europe at the same time) has been introduced. For several reasons, it was not possible to apply this method here, not least because Triadic patents only reflect a small subset of all patent filings and their topicality is restricted. Since we are more interested in the question of who applies for patents, and less in the question of where they are applied for or how internationally relevant and "profitable" these filings are, we decided to use only EPO patent applications (including all filings that enter the EPO via the PCT (Patent Cooperation Treaty) route). 
performance, we used information provided by the EPO via the so-called PATSTAT 8 database. By combining several databases, we have been able to set up a complete database, containing all relevant information in a form that we could combine with the country-specific lists of first names. Due to certain characteristics of the application procedure and the fact that there are at least three ways in which one can chose to file an EPO patent, our analysis ends in the year 2005. This is the latest year for which data are completely available at the time of data extraction.

Scientific publications, on the other hand, are the most important output of the (public) research system (Moed et al., 2004; Van Raan, 1988). These range from conference proceedings, reviews, and books to journal articles. In this paper, we focus on the latter as they systematically reflect - in many scientific fields, at least - the most recent findings. Whereas the production of books and conference proceedings are dependent on less systematic factors, the number of articles in scientific journals is less erratic, and changes in structure and trends can therefore be more readily interpreted.

Just as for patent applications, it is essential for the publication analysis to have the full first names in order to identify the gender of the authors. Unfortunately, most databases on scientific papers abbreviate those first names, even if they are available in the journal. For example, the Science Citation Index uses only the initials of the first names. 9 Fortunately, a new database has been set up by Elsevier, which is called 'Scopus'. 10 Besides a very extensive coverage of journals from all scientific areas, a database on authors has been established by integrating various information sources; this gives the full first name for most authors, provided the name is available somewhere in the database. Based on an extraction of information from the 'Scopus' database that Elsevier provided us with, we analysed the respective contributions of male and female researchers to the research system in selected countries. 11 On the basis of

8 EPO Worldwide Patent Statistics Database, further referred to as PATSTAT.

9 Another methodological approach is described in Mauleón and Bordons (2006).

$10 \mathrm{http}: / / \mathrm{www}$. scopus.com/ (accessed on 19.04.2007).

11 Similar to the Science Citation Index, Scopus covers mainly internationally relevant journals, which - as a matter of fact - are mainly in English. On the other hand, the journals are not only in English, but the database also covers national journals in national languages. However, English-speaking countries are over-represented in the database. This bias would even be higher in social sciences and humanities, which we excluded from our analyses, as these scientific areas are much more nationally oriented. Furthermore, since we use relative instead of absolute indicators, the language bias should be mostly compensated. 
their impact factors 12 , about 300 leading journals in eight scientific areas were chosen, and the data for a period from 1996 to the present was analysed, using the same broad approach as for the patent analysis.

Comprehensive and country-specific lists of first names, as first developed by Naldi et al. 2000a, 2000b, were applied to the database of patent applications as well as to the publications for a selection of leading countries. 13 The subtle 'country-specific' distinction is not only necessary to later obtain information on the country-specific research activities of female scientists, but also because the associated gender of certain first names occasionally varies between countries; in other words, a name may be used for men in one country, whereas the same name in another country may be a typical female first name. 14 With this procedure, in many cases the gender of the inventors or authors can be assigned reasonably unambiguously. However, in some cases, the gender cannot be identified, for example because of 'foreign' first names. This is due to the fact that, in a given country, some people may have migrated from other countries, while some names from other languages or cultures may also have diffused into that society. In the present study, only countries with a maximum of $15 \%$ of unknown names have been included, implying that the gender of the author could be attributed in at least $85 \%$ of the names. Employing this strategy on patent applications yielded 14 countries for further analysis. To facilitate the comparison of results, the same 14 countries were chosen for the publication analysis.

There is a series of indicators that are commonly used to measure the patenting and publishing activity of scientists (cf. Naldi et al. 2002, 2004; Burkhardt and Greif 2001). Different 'dimensions' of measurement can be distinguished - for example, the frequency of publishing or patenting, the extent of collaboration with others, and the utilization of the results of the research or technological activities. The choice of the most suitable indicator is determined by the underlying research question. There is no single index of scientific or technological output that is completely adequate or universally accepted (cf. Long, 1992). The present study focuses on measuring the degree of involvement of women in technological and scientific activities. To determine their involvement, several indicators need to be taken into account.

12 For a detailed description of the computation of the impact factor, see http://scientific.thomson.com/free/essays/journalcitationreports/impactfactor/ (22.07.2008).

13 Australia, Austria, Belgium, Denmark, France, Germany, Ireland, Italy, New Zealand, Spain, Sweden, Switzerland, the United Kingdom and the USA.

14 For example, 'Andrea' is a masculine first name in Italy, but a feminine first name in Germany. 
The first possibility is to compute the proportion of teams with at least one woman involved. This index counts any patent application (or publication) in which a woman is involved. The actual number of women per team has no impact on the value of this particular indicator. A second possibility is to calculate the proportion of women in relation to all inventors or researchers. The actual number of patent applications (or publications) does not have any influence on the value of this indicator. The team size is not considered in either the first nor the second possibility. However, since we consider the team size to be quite relevant when determining the actual technological and scientific contribution of women, we decided to choose an indicator that includes the number of patent applications (or publications), the share of women per patent application (or publication) and the team size. 15

The calculation involves several steps. First, the share of women/men per team is computed assuming a uniform contribution: for example, if five inventors (including two women) together apply for a patent, each of them is assumed to contribute $1 / 5^{\text {th }}$, and the share of women then is $2 / 5^{\text {th }}$. Second, the sum of these shares over all patent applications (or publications), differentiated by sex, is calculated. Finally, this sum is divided by the total number of patent applications (or publications) in the sample. To put it in other words, the contribution of men and women is calculated on the basis of 'fractional counts' of co-inventors (or co-authors). 16

\section{$4 \quad$ Data}

\subsection{Patent Applications}

Patent applications for five priority years $(1993,1996,1998,2000,2001)$ and 14 countries were gathered using the filings to the EPO. In total, the analysis was successfully performed for 2413438 inventors. 'Successful' refers to our ability to ascertain both the nationality 17 and the gender of an inventor; in some cases, the full first name and nationality of an inventor is given, but the analysis could not be accomplished due to

15 The results based on the two other indicators are available on request.

16 Fractional counting is an established technique in bibliometric analysis when dealing with multi-author or multi-institutional publications.

17 The inventor comes from one of the 14 countries considered here. 
the difficulty mentioned earlier of dealing with 'foreign' first names. 18 Further analysis proved that the majority of inventors came from the United States (35.2\%) and Germany $(29.4 \%)$. In the dataset, the other countries had shares well below $10 \%$; Ireland and New Zealand had shares of less than $0.3 \%$, which is due both to their size and to their 'distance' from, or 'orientation' towards, the EPO. All values have been suitably rounded.

\subsection{Publications}

Publication data for four years $(1996,2000,2002,2005)$ and for 14 countries were extracted electronically from the Scopus database. In total, data on 274921 publications were extracted. From these, we were able to make use of 161583 (58.77\%) publications (where full first names were given, where at least one author came from one of the 14 countries considered here, and where the gender of the named authors could be ascertained 19). As with the patent application data, the 'hit rate' for the publication data varied across countries 20 . In general, the percentages fell below those for the patent data. One possible explanation for this could be the high mobility of researchers: as researchers migrate into other countries and publish their work, their first name may not be on our list for that country and therefore cannot be assigned a gender using the first-name database.

In total, the extracted data included 1322102 authors. 490244 names (131 160 $(26.75 \%)$ of which were female) could be used for further analysis. The remaining 831 858 names $(62.9 \%)$ are not included in the first-name database and therefore could not be processed further. Considering the distribution of authors in terms of their nationality, a similar picture as for the patent application data is revealed: the majority of authors originate from the United States of America (53.6\%), 11.0\% percent of the au-

18 The respective shares of identified inventor names in relation to the total number of names per country from 1991 to 2005 (in \% terms) were as follows: AUT (97.0), GER (96.9), ITA (95.8), FRA (94.0), SUI (93.3), ESP (92.7), GBR (92.1), NZL (90.6), IRL (90.6), BEL (89.0), SWE (89.0), AUS (88.8), DEN (88.2), USA (81.1). In the case of multilingual countries such as Switzerland (German, Italian, French) and the United States of America (English, Spanish), more than one name list was employed.

19 i.e. it was possible to identify the gender by applying our first-name database. Scopus provides full first names for the authors, if these are available in the journals.

20 The respective shares of identified author names in relation to the total number of names per country from 1996 to 2005 (in \%) were as follows: AUT (93.1), AUS (82.8), BEL (78.0), SUI (90.4), GER (91.9), DEN (77.3), ESP (86.1), FRA (89.8), GBR (84.3), IRL (85.1), ITA (94.5), NZL (84.3), SWE (85.4), USA (75.6). In the case of multilingual countries such as Switzerland (German, Italian, French) and the United States of America (English, Spanish), more than one name list was employed. 
thors come from Germany. In the dataset, the other countries had shares below $10 \%$; Ireland and New Zealand had shares of less than $0.5 \%$. All values have again been rounded.

The publications were assigned to eight research areas. 21 Since the distribution in the extracted database and the distribution in the complete database did not match exactly, the data in the former were weighted accordingly. Table 1 shows the distribution in the extracted database and in the complete database for the year 2005. As can be seen, the scientific areas 'Earth and Space' and 'Mathematics' were under-represented. Therefore, publications from these two scientific areas were multiplied by a factor of 2.53 and of 2.26 respectively. The weightings for the other scientific areas were all smaller than one, meaning that these scientific areas were more strongly represented in the extracted database than in the complete database. This bias could be adjusted with the corresponding weightings. On the basis of this adjustment, the distributions in the extracted database and in the complete database could be assimilated. As a result of the adaptation, minor changes of the indicator values occurred. However, there is a strong positive correlation between the weighted and unweighted indicator values (with a correlation coefficient $>95 \%$ ).

Table 1: Distribution of scientific areas in the extracted database and in the complete Scopus database

\begin{tabular}{|l|c|c|c|c|c|}
\hline Scientific Areas & $\begin{array}{c}\text { \# publications } \\
\text { (excerpt) }\end{array}$ & $\begin{array}{c}\text { \% of publ. } \\
\text { (excerpt) }\end{array}$ & SCOPUS & $\begin{array}{c}\% \\
\text { scOPUS }\end{array}$ & Weights \\
\hline Biology & 5007 & 12.3 & 97863 & 6.6 & 0.53 \\
\hline Biomedical Sciences & 5831 & 14.3 & 162726 & 10.9 & 0.76 \\
\hline Chemistry & 5861 & 14.4 & 167408 & 11.2 & 0.77 \\
\hline Earth and Space & 3721 & 9.2 & 346334 & 23.3 & 2.53 \\
\hline Engineering & 3324 & 8.2 & 102213 & 6.9 & 0.84 \\
\hline Clinical Medicine & 9989 & 24.6 & 337812 & 22.6 & 0.92 \\
\hline Mathematics & 1363 & 3.4 & 114046 & 7.7 & 2.26 \\
\hline Physics & 5547 & 13.6 & 160847 & 10.8 & 0.79 \\
\hline TOTAL & 40643 & 100.0 & 1488949 & 100.0 & \\
\hline
\end{tabular}

Source: Elsevier: Scopus; own computations

21 To ease comparability, similar fields were chosen as for the patent applications. Social sciences and humanities are not considered, due to the lack of patentability. Furthermore, the English language bias deters from an internationally comparative analysis of these fields. Certainly, in these fields the share of women might significantly differ from the share of women in science and technology. 


\section{$5 \quad$ Results}

\subsection{Patent Applications}

As already mentioned, we restrict our analysis to one of the three possible indicators, namely the respective 'contribution' of men and women, which is the sum of the fractional counts of men's and women's contribution to patents. 22 It can be seen from Table 2 that the relative contribution of women over the years 2003-2005 - averaged across all technological fields - is highest in Spain (12.3\%), followed by France $(10.2 \%)$ and a group of countries with similar levels (of more than $8 \%$ ) consisting of Denmark, Australia, the USA, Belgium and Sweden. At the lower end of the scale, Germany $(4.7 \%)$ and Austria (3.2\%) rank last, a considerable distance from those to the top. The general trend over time has been a strong increase in women's contribution to technology output in most countries, but it is still at a relatively low level. Moreover, the growth rates have flattened out since 1996 in most countries and a dynamic increase is hardly visible anymore. After 2001, the share accounted for by women actually decreased in the USA, while it stagnated in France, Denmark and Switzerland. 23

Table 2: Women's 'contribution' (patent applications), 1991-2005

\begin{tabular}{|l|c|c|c|c|c|}
\hline & $\mathbf{1 9 9 1}$ & $\mathbf{1 9 9 6}$ & $\mathbf{2 0 0 1}$ & $\mathbf{2 0 0 5}$ & $\mathbf{2 0 0 3 - 2 0 0 5}$ \\
\hline ESP & $7.5 \%$ & $9.3 \%$ & $11.1 \%$ & $14.2 \%$ & $12.3 \%$ \\
\hline FRA & $6.0 \%$ & $7.5 \%$ & $9.9 \%$ & $9.9 \%$ & $10.2 \%$ \\
\hline DEN & $5.0 \%$ & $8.7 \%$ & $8.1 \%$ & $8.2 \%$ & $8.9 \%$ \\
\hline AUS & $4.4 \%$ & $6.1 \%$ & $12.2 \%$ & $8.1 \%$ & $8.3 \%$ \\
\hline USA & $6.3 \%$ & $7.7 \%$ & $8.8 \%$ & $8.2 \%$ & $8.3 \%$ \\
\hline BEL & $5.0 \%$ & $6.6 \%$ & $7.9 \%$ & $8.4 \%$ & $8.1 \%$ \\
\hline SWE & $5.2 \%$ & $4.8 \%$ & $6.7 \%$ & $8.6 \%$ & $7.6 \%$ \\
\hline ITA & $4.9 \%$ & $5.1 \%$ & $6.7 \%$ & $7.6 \%$ & $7.4 \%$ \\
\hline NZL & $2.1 \%$ & $6.6 \%$ & $10.1 \%$ & $7.2 \%$ & $6.7 \%$ \\
\hline GBR & $4.0 \%$ & $5.7 \%$ & $6.2 \%$ & $6.7 \%$ & $6.4 \%$ \\
\hline IRL & $3.5 \%$ & $6.9 \%$ & $7.4 \%$ & $7.9 \%$ & $6.4 \%$ \\
\hline
\end{tabular}

22 The results based on the other indicators are available on request.

23 The data for New Zealand, Ireland and even Austria cannot readily be interpreted on a year-by-year basis due to the very low absolute numbers of female patents, which strongly affects the relative values. 


\begin{tabular}{|l|l|l|l|l|l|}
\hline & 1991 & 1996 & 2001 & 2005 & $2003-2005$ \\
\hline SUI & $1.6 \%$ & $3.3 \%$ & $5.7 \%$ & $5.9 \%$ & $5.9 \%$ \\
\hline GER & $2.4 \%$ & $3.2 \%$ & $4.5 \%$ & $4.9 \%$ & $4.7 \%$ \\
\hline AUT & $2.2 \%$ & $3.1 \%$ & $3.3 \%$ & $2.9 \%$ & $3.2 \%$ \\
\hline
\end{tabular}

Source: EPO: PATSTAT; own computations

Some explanation for the differences between the countries can be found in Table 3 , where a breakdown of women's contribution by 19 technological fields is provided based on the main IPC classes. Small countries - in terms of European patent applications - are excluded from this table, although their results are included in the 'Total' column.

Table 3: Shares of women's contribution by technological fields, 2003-2005 (in percent)

\begin{tabular}{|c|c|c|c|c|c|c|c|c|c|}
\hline & SUI & GER & ESP & FRA & GBR & ITA & SWE & USA & $\begin{array}{l}\text { To- } \\
\text { tal }\end{array}$ \\
\hline Pharmaceuticals & 18.9 & 19.4 & 26.4 & 32.9 & 16.2 & 28.3 & 26.4 & 18.8 & 21.0 \\
\hline Basic chemicals & 9.2 & 9.1 & 15.8 & 16.5 & 12.0 & 15.7 & 10.3 & 11.0 & 11.1 \\
\hline Textiles, furniture, food & 5.1 & 5.7 & 10.8 & 8.6 & 9.0 & 5.4 & 7.5 & 10.7 & 7.7 \\
\hline Polymers, rubber etc. & 6.1 & 5.5 & 11.4 & 8.9 & 5.0 & 7.9 & 5.8 & 8.4 & 7.2 \\
\hline Medical equipment & 3.2 & 5.1 & 15.4 & 6.8 & 6.0 & 7.4 & 17.3 & 6.8 & 6.6 \\
\hline Electronic components & 2.7 & 3.8 & 8.8 & 10.3 & 5.0 & 9.7 & 6.8 & 6.5 & 6.3 \\
\hline Optics & 9.9 & 4.6 & 10.2 & 10.3 & 7.5 & 5.6 & 1.9 & 6.3 & 6.2 \\
\hline Non-polymer materials & 3.8 & 4.1 & 11.8 & 9.2 & 3.4 & 4.2 & 15.1 & 7.7 & 6.0 \\
\hline Measurement, control & 4.2 & 3.7 & 12.0 & 8.3 & 5.7 & 8.2 & 6.6 & 7.0 & 5.8 \\
\hline Computers, office machinery & 4.0 & 2.9 & 1.1 & 6.3 & 2.7 & 5.0 & 3.6 & 6.7 & 5.4 \\
\hline Audio-visual electronics & 6.0 & 1.9 & 4.9 & 7.9 & 2.9 & 9.3 & 0.0 & 7.3 & 5.4 \\
\hline Telecommunications & 1.6 & 2.3 & 8.5 & 8.2 & 3.8 & 8.2 & 3.1 & 6.5 & 5.2 \\
\hline Electrical machinery, energy & 2.5 & 1.9 & 3.9 & 4.3 & 5.6 & 4.8 & 1.0 & 3.7 & 3.0 \\
\hline Metal products & 3.9 & 2.4 & 3.8 & 1.9 & 2.9 & 2.8 & 3.8 & 5.7 & 3.0 \\
\hline Special machinery & 2.6 & 2.0 & 8.2 & 3.9 & 3.4 & 2.4 & 4.9 & 3.9 & 2.8 \\
\hline General machinery & 2.0 & 2.2 & 4.8 & 5.4 & 1.3 & 1.6 & 2.2 & 3.7 & 2.7 \\
\hline Transport & 2.0 & 2.0 & 3.9 & 3.6 & 2.0 & 2.6 & 5.1 & 3.3 & 2.6 \\
\hline Energy machinery & 0.9 & 1.2 & 4.5 & 3.7 & 2.8 & 3.4 & 1.3 & 3.2 & 2.2 \\
\hline Machine-tools & 1.6 & 0.9 & 0.0 & 4.0 & 1.5 & 0.8 & 2.3 & 3.5 & 1.8 \\
\hline
\end{tabular}


Pharmaceuticals has the highest women's contribution $(21 \%)$ and is at the same time one of the largest fields in terms of patent filings analysed here, thus accounting for the highest weight in the distribution of many countries. Basic Chemicals ranks second in this list of technological fields, though a substantial way behind Pharmaceuticals. In the middle of the range, the Electronics and Electrical Equipment fields can be found along with Telecommunications and Computers. At the lower end are the engineering technologies, where the shares corresponding to women's contribution to technology production fall below $4 \%$. Furthermore, these patterns seem to hold - more or less - for all countries under observation here. Consequently, in countries where Pharmaceuticals or Basic Chemicals play a major role, the women's contribution tends to be higher, while in countries that are more active in engineering it is lower.

Comparisons across countries show similar patterns with a few interesting exceptions. Germany is below the average in all fields, with some technological areas like Audiovisual Electronics or Telecommunications being - in relative terms - much lower than the average. Spain, in contrast, is far ahead in Chemistry and related fields, whereas the women's share is rather low in Electronics and the like. Most interesting to note are the low shares of female patenting in the USA in the top two fields of Pharmaceuticals and Basic Chemicals. Overall, the USA comes below the international average. For smaller countries, such a result might be explained by size effects, but not apparently in the case of the USA.24 This result casts light on the above finding concerning the decreasing total female share in the USA. Especially in Chemistry-related fields, a relative decrease in female patenting is visible, whereas the shares in most other countries were increasing over the same period, with the result that the total female share has been stagnating since 2000 (see Figure 1).

24 In the three-year period 2003-2005, the female contribution to the US patent portfolio accounts for 354 (fractional) patents in Basic Chemicals and 1325 in Pharmaceuticals. 
Figure 1: Total* $^{*}$ shares of women's contribution to technology output in five technology areas, 1991-2005

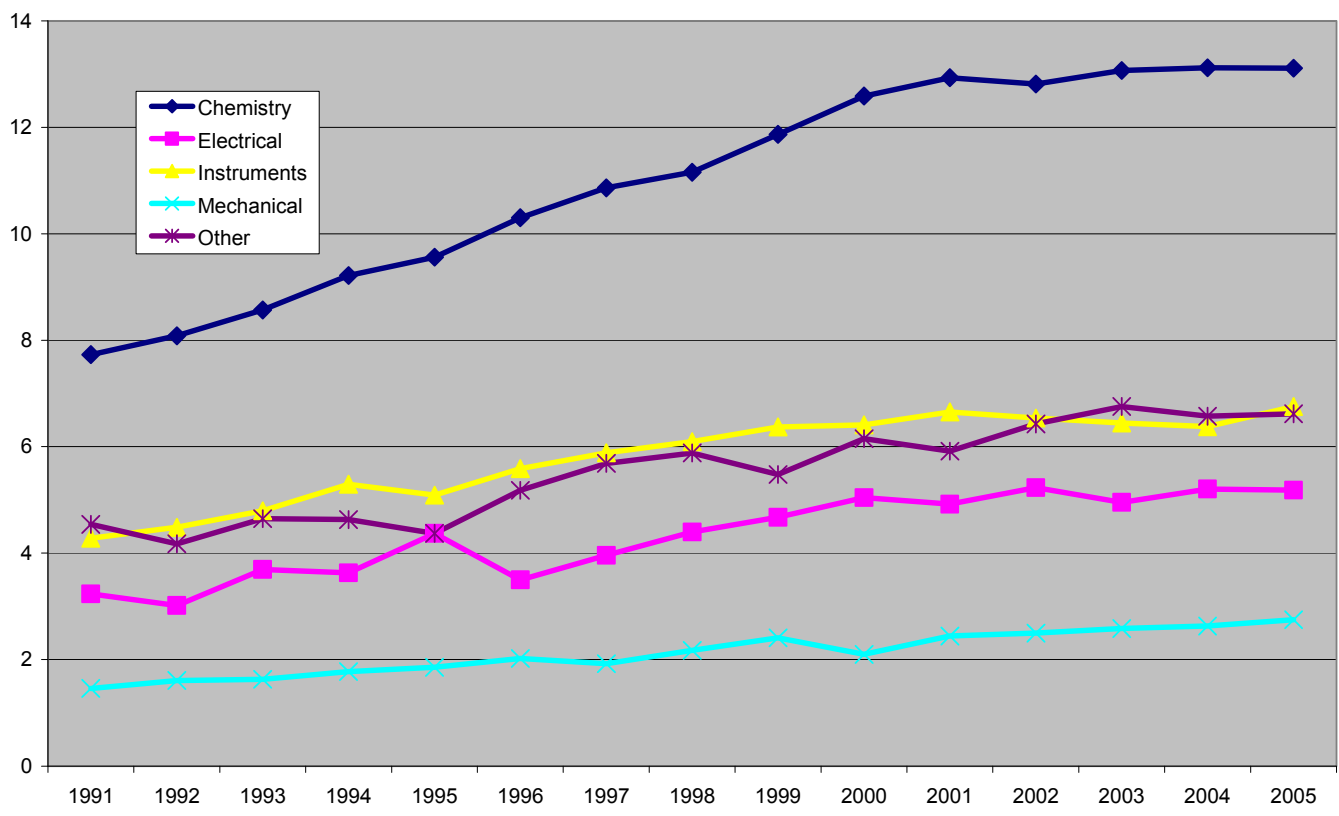

* Total includes all 14 countries included in the study

Source: EPO: PATSTAT; own computations

\subsection{Publications}

Likewise in the case of publications, focussing on one indicator only - women's relative 'contribution' as calculated from the fractional count of female authorship - is advisable in order to keep the discussion clear. 25 It should be noted that women's percentage contributions are higher for publications than for patents in any country (see Table 4). The values for the year 2005 vary between $17.5 \%$ for Ireland and $30.4 \%$ for Italy, while the minimum and maximum values for patent filings in $2003-2005$ were $3.2 \%$ and $12.3 \%$, respectively.

25 The publication data have been weighted according to the procedure described above for patents. 
Table 4: Shares of women's 'contribution' (publications), 1996-2005

\begin{tabular}{|l|l|l|l|l|}
\hline & $\mathbf{1 9 9}$ & $\mathbf{2 0 0 0}$ & $\mathbf{2 0 0 2}$ & $\mathbf{2 0 0 5}$ \\
\hline ITA & $27.8 \%$ & $26.6 \%$ & $29.3 \%$ & $30.5 \%$ \\
\hline ESP & $26.8 \%$ & $27.1 \%$ & $30.4 \%$ & $28.0 \%$ \\
\hline FRA & $27.1 \%$ & $27.6 \%$ & $26.5 \%$ & $27.7 \%$ \\
\hline SWE & $16.7 \%$ & $21.3 \%$ & $24.0 \%$ & $24.5 \%$ \\
\hline BEL & $17.1 \%$ & $22.0 \%$ & $24.1 \%$ & $24.2 \%$ \\
\hline USA & $20.6 \%$ & $21.4 \%$ & $22.6 \%$ & $24.1 \%$ \\
\hline GBR & $18.4 \%$ & $19.2 \%$ & $20.7 \%$ & $22.7 \%$ \\
\hline DEN & $16.1 \%$ & $18.7 \%$ & $20.6 \%$ & $22.0 \%$ \\
\hline AUS & $17.3 \%$ & $21.4 \%$ & $22.0 \%$ & $21.4 \%$ \\
\hline GER & $15.2 \%$ & $15.2 \%$ & $17.8 \%$ & $19.2 \%$ \\
\hline NZL & $10.9 \%$ & $16.4 \%$ & $19.1 \%$ & $18.9 \%$ \\
\hline AUT & $16.7 \%$ & $16.0 \%$ & $19.5 \%$ & $18.7 \%$ \\
\hline SUI & $15.5 \%$ & $16.6 \%$ & $18.0 \%$ & $18.3 \%$ \\
\hline IRL & $13.7 \%$ & $18.1 \%$ & $24.1 \%$ & $17.5 \%$ \\
\hline
\end{tabular}

Source: Elsevier: Scopus; own computations.

The women's relative contribution to scientific publications is highest in Italy, France and Spain. While France and Spain also performed very well in terms of patents, the high ranking of Italy is somewhat surprising as it ranks below average in terms of patents. Germany, Austria and Switzerland are again at the lower end of the distribution, a result that fits in with the earlier findings from the patent analysis. New Zealand and Ireland show low levels of women's contributions to scientific publications, which was not the case for patents to the same extent. The reasons for this cannot be established with any certainty at this point, but it is obvious that one cannot simply extrapolate from men's and women's engagement in science to their relative contributions to scientific output. Issues such as employment rates in public and private research, the role of public and private employment in the economy, the level of involvement in different scientific and technological fields, and so on, all have to be considered as well as the previously mentioned structural factors. Germany, for example, has relatively low shares of female researchers in both the public and the private sector. Ireland, on the other hand, has a comparatively high share of women in the public sector, but a relatively low share of women in industry. Furthermore, looking at the shares of female researchers in the higher education sector, Ireland is among the top countries in Eu- 
rope 26 - a finding that is in direct contradiction to our findings on the output of women in these countries, both in patenting and publishing.

Figure 2: Total ${ }^{\star}$ shares of women's contribution to scientific output, 1996-2005

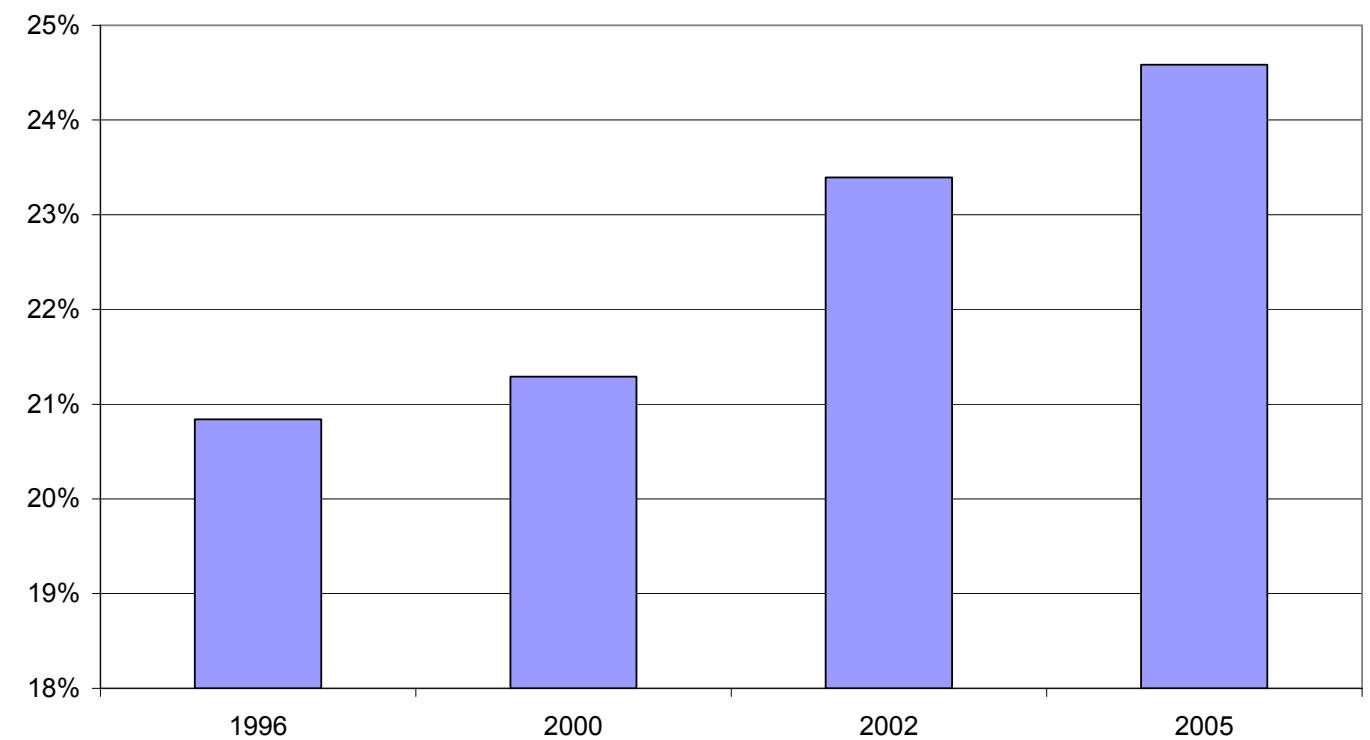

* Total includes all 14 countries included in the study

Source: Elsevier: Scopus; own computations

It is interesting to note that the data on women's share of publications - unlike the results for patents - hardly increase over time for the already better-performing nations. The shares for Italy, Spain or France - as shown in Table 4 - have remained fairly constant over the 10-year period under examination here. However, if we take all 14 countries (see Figure 2), an increasing trend is visible - even stronger than in the case of patent filings - especially after the year 2000. Among the fastest growing countries are Sweden, Belgium, Denmark and New Zealand, which increased their shares of women's output by nearly $50 \%$ or more. In short, the overall trend is driven not so much by the already better performing nations in terms of female publishing but by a catching-up of other, lower-placed nations.

Analysing the different research areas for the year 2005, we see that approximately one quarter $(24.7 \%)$ of the publications come from the field of Clinical Medicine. In the dataset, the field with the fewest publications is Mathematics (3.3\%). Regarding the

26 The data are for 2004, and are derived from Eurostat: New Cronos; see http://epp.eurostat.ec.europa.eu. 
shares of women's contribution in each research area (see Table 5), Biology turns out to have the highest share (33\%) and Mathematics the lowest (16.5\%). And these relations are more or less similar across all five countries under detailed consideration here. 27 Except for Geo-science in the countries of Germany, France and the United Kingdom, a field that ranks higher in these countries than on average for all 14 countries, the ranking is close to that for the total. Of note are the high shares of Chemistry and Engineering in Italy, which has a considerable impact on the relatively high value of $30.4 \%$ for Italy as a whole across all scientific fields, while Biology and Bio-Medicine show nearly equal shares for men and women, although these are too small to have a major impact on the Italian total. Germany performs especially badly in Chemistry and Clinical Medicine, while the distance behind the average is not too large in Biology and Bio-Medicine.

Table 5: Shares of women's contribution by scientific areas, 2005 (in percent)

\begin{tabular}{|l|l|l|l|l|l|l|l|l|l|}
\hline & SUI & GER & ESP & FRA & GBR & ITA & SWE & USA & $\begin{array}{l}\text { To- } \\
\text { tal }\end{array}$ \\
\hline Biology & 27.2 & 30.1 & 36.9 & 40.8 & 30.6 & 48.4 & 27.6 & 32.3 & 33.0 \\
\hline Bio-Medicine & 28.4 & 26.4 & 39.8 & 36.7 & 29.5 & 44.2 & 33.5 & 30.2 & 31.5 \\
\hline Clinical Medicine & 19.2 & 18.5 & 28.4 & 29.0 & 23.9 & 31.9 & 28.4 & 26.1 & 25.9 \\
\hline Chemistry & 19.3 & 15.8 & 34.8 & 26.8 & 22.4 & 41.2 & 25.8 & 22.1 & 23.8 \\
\hline Geo-science & 17.1 & 22.3 & 30.4 & 28.8 & 24.4 & 23.8 & 23.9 & 22.3 & 23.0 \\
\hline Engineering & 17.2 & 15.7 & 27.5 & 24.6 & 16.6 & 31.8 & 22.2 & 18.9 & 20.2 \\
\hline Physics & 10.9 & 12.5 & 18.5 & 20.6 & 15.3 & 20.2 & 14.8 & 18.2 & 17.2 \\
\hline Mathematics & 12.6 & 11.7 & 13.5 & 16.1 & 13.0 & 19.6 & 12.9 & 17.9 & 16.5 \\
\hline
\end{tabular}

* Total includes all 14 countries analysed in the study

Source: Elsevier: Scopus; own computations

27 The same countries have been chosen as in the patent analysis, although the absolute numbers of publications would have allowed us to analyse rather more countries. The "Total" column contains all 14 countries analysed in our dataset. 


\section{$6 \quad$ Discussion and Outlook}

During the past ten years, women's share of the output in technology and science has generally increased across the 14 countries under consideration - as measured by the indicator of contribution used here, which was defined as the fractional count of women inventors (of patents) or authors (of scientific papers). Although the picture is not always completely clear, the central European countries of Germany, Austria and Switzerland have rather low female contributions, whereas Spain, France and also Italy show high female shares in terms of scientific output and partly also in technological output, as measured by publications and patents, respectively. Countries like Sweden, Denmark, Belgium, Australia, or the USA come towards the middle in terms of women's contributions, at least compared to the set of countries examined in this study.

One reason for these differences that was given in the empirical section concerns differences in industry or research structure. Some countries are more specialised in certain scientific or technological areas where women are more likely to be engaged, such as Biology or Pharmaceuticals. However, this still does not explain all the differences. Nor does it explain if this is a prerequisite for, or a consequence of, the varying structure of the industry/science systems in different countries. Further research on this is needed.

Another explanation might relate to the relative cost of childcare. For the UK, Viitanen (2005) found that childcare subsidies do not apparently influence the labour force participation of women or the use of formal childcare to a significant extent. On the other hand, Chiuri (2000) found that in Italy the cost of childcare does have an impact on a household's decision over childcare and labour supply. Although there is no consensus on whether the cost of childcare does or does not affect the decision of women to work, at least in individual cases it would seem that the cost of childcare may significantly influence a woman's choice to work. Figure 3 suggests that there is a connection between the childcare system and the shares of women's scientific output, except for outliers like Denmark and perhaps also Germany and Austria. 
Figure 3: Shares of women's contribution (publications) 2005 and expenditure on pre-primary education as a share of GDP 2004

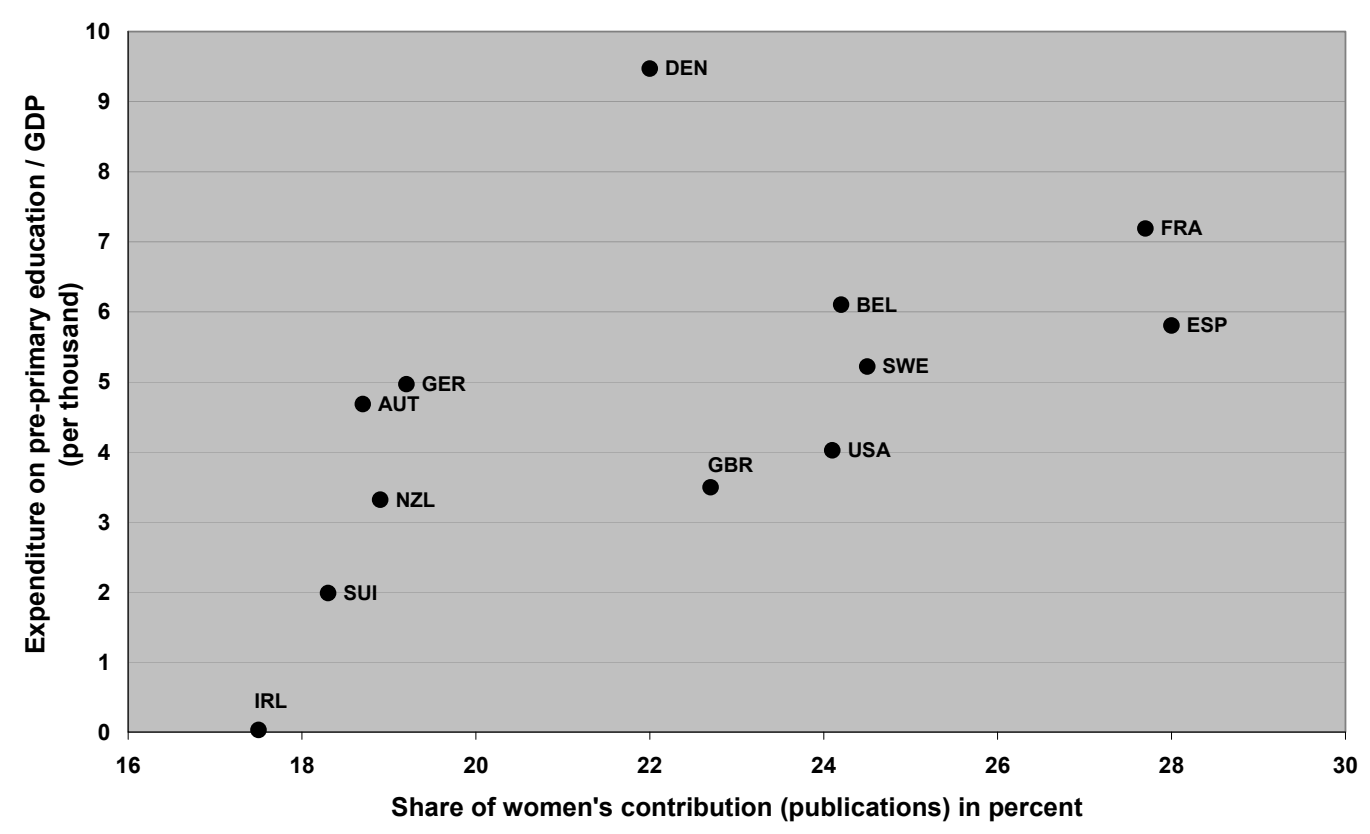

Source: EU-Commission (2007), EPO: PATSTAT; own computations

Further explanations for the differences between the countries can only be based on anecdotal evidence, since a direct empirical link to the inputs is not yet possible. A higher proportion of women active in R\&D in general and especially in the private economy - where most of the patents are filed - is one possible explanation. A higher proportion of female graduates or researchers is - of course - an important input to technology production.

Differences regarding the contribution of women across countries could be the result of structural differences in the labour market, for example, income differences or differences in the pursuit of part-time activities. Interestingly, Italy and Spain, which according to our analysis have the highest relative contribution of women, seem to have relatively low annual average incomes for researchers (European Commission 2007, p. 56). Germany and Austria, on the other hand, rank last in our sample, while in these countries the annual average remuneration is comparatively high. At least with regard to the shares of women in patenting, a negative correlation seems to be evident (see Figure 4), with only two outliers (USA and Italy). The higher the income of (public and) private researchers, the lower the representation of women. Or to put it the other way around: if researchers are paid comparatively well, the representation of men is higher. However, this correlation is only found for patenting activities. 
Figure 4: Shares of women's contribution (patents) 2003-2005 and remuneration of researchers 2006

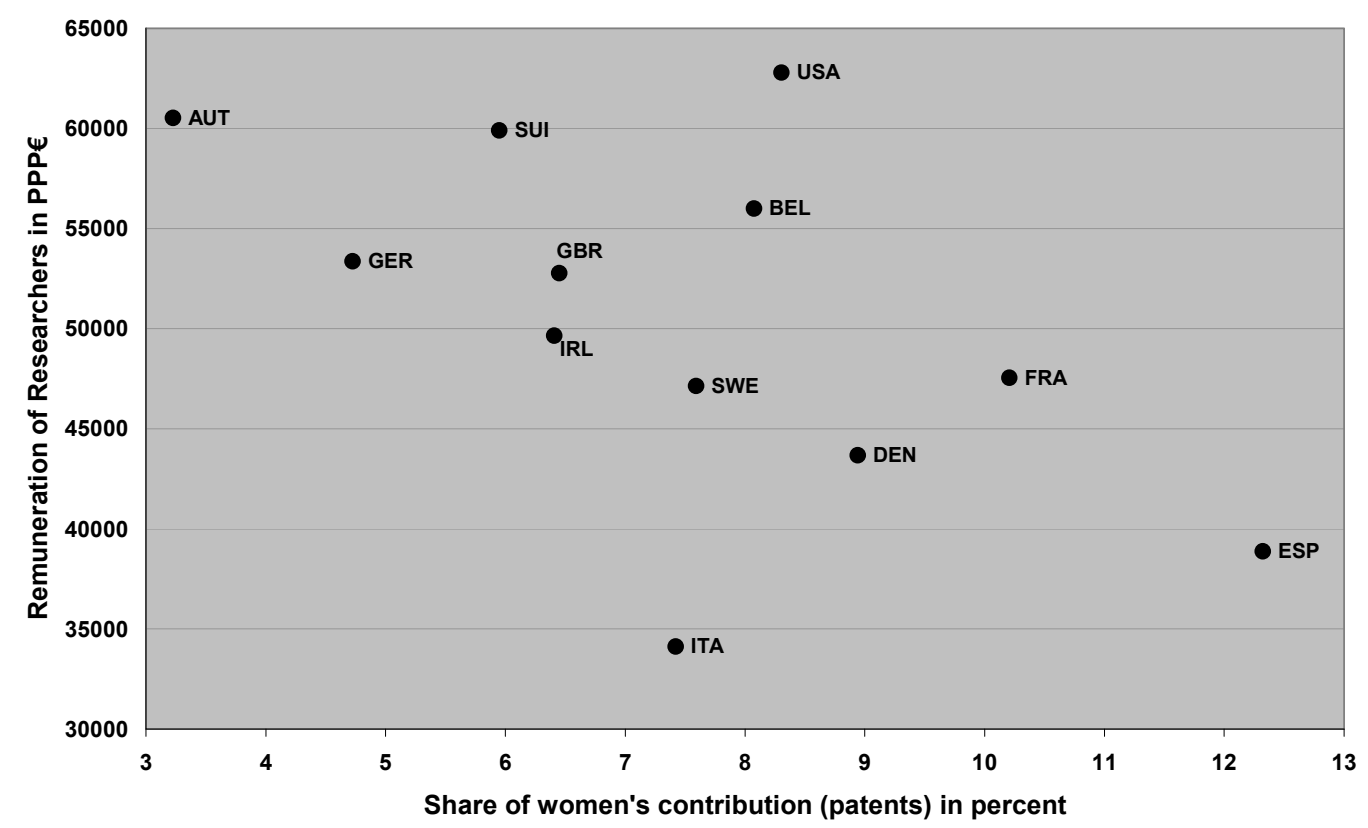

Source: EU-Commission (2007), EPO: PATSTAT; own computations

Further studies could focus on verifying the possible explanations offered here or on finding other explanations for the country- and discipline-specific differences that we have identified. To do so, links between the dataset and additional information are necessary. In particular, input factors like the number of graduates or the number of researchers have to be directly related to the suggested output indicators. Multivariate statistical models could be employed to test how the R\&D output performance varies under the assumption of given R\&D input differences. Furthermore, the obstacles and reasons for women to avoid specific research fields, or the reasons for the proportionally higher percentage of southern European female researchers, could be the subject of further research projects.

Often gender-mainstreaming discussions have tended to focus on the inputs to R\&D; among the topics considered are equality in the distribution of inputs, access to resources, chances of success in obtaining support, relative enrolment levels and numbers of R\&D staff. In this paper, it was not the intention to quantify and assess the quality of men's and women's respective outputs in science and technology, nor was it possible to relate inputs and outputs directly. Therefore, it would not be meaningful to interpret the reported data as representing an evaluation of outputs. Proven reasons for the various differences across countries cannot be given and possible explanations for differences among the countries can only be suggested on the basis of anecdotal evidence. Instead, the intention was to examine the output side of technology and science 
in the form of patents and publications, and thereby to enrich the spectrum of possible indicators to use in the discussion of differences relating to gender. While the reasons may be manifold, the fact is that in most countries a positive development is visible, indicating an increasing utilisation of female human capital in science, technology and innovation.

The procedures presented here will, we hope, inspire future research projects to gather further data. The availability and easy accessibility of large-scale databases of reliable quality might open up new approaches and new analyses. We have been able to demonstrate that both patent and publication data are ready to be used by other researchers in future research projects. Furthermore, we hope that the suggested gender indicators will enrich the statistical analysis of innovation systems, offering another standard indicator to describe the modernity and future orientation of economies, sectors or regions. The extension of this approach to other countries and to further cohorts of authors and inventors is an important future task. 


\section{$7 \quad$ References}

Ammermüller, A., Weber, A.M., 2005. Educational Attainment and Returns to Education in Germany - An Analysis by Subject Degree, Gender and Region, ZEW Discussion Paper No. 05-17, Mannheim.

Bunker Whittington, K.C., 2006. Gender and Scientific Dissemination in Public and Private Science: A Multivariate and Network Approach. Department of Sociology, Stanford University.

Bunker Whittington, K.C., Smith-Doerr, L., 2005. Women and Commercial Science: Women's Patenting in the Life Sciences. Journal of Technology Transfer, 30, 355-370.

Burkhardt, D., Greif, S., 2001. Frauen im Patengeschehen der Bundesrepublik Deutschland. Bundesministerium fuer Bildung und Forschung, Bonn.

Chiuri, M.C. (2000), Quality and Demand of Child Care and Female Labour Supply in Italy, Labour 14(1), 97-118.

Cole, J.R., Zuckerman, H., 1984. The Productivity Puzzle: Persistence and Change in Patterns of Publication Among Men and Women Scientists In: Steinkamp, M.W., Maehr, M. (Eds.): Advances in Motivation and Achievement. JAI Press, Greenwich.

Ding, W. W., Murray, F., Stuart, T. E., 2006. Gender Differences in Patenting in the Academic Life Sciences. Science, 313 (5787), 665-687.

Duschek, K.-J., Wirth, H., 2005. Kinderlosigkeit von Frauen im Spiegel des Mikrozensus. Eine Kohortenanalyse der Mikrozensen 1987 bis 2003. Wirtschaft und Statistik, 8/2005, 800-820.

Ehrenberg, R.G., Smith, R.S., 2003. Inequality in Earnings - Modern Labor Economics - Theory and Public Policy. Addison Wesley, Boston, pp. 471-502.

European Commission, 2005. Proposal for a Regulation of the European Parliament and of the Council establishing a European Institute for Gender Equality. COM (2005) 81 final, Commission of the European communities, Brussels.

European Commission, 2007. Remuneration of Researchers in the Public and Private sectors, Final Report, EC: Brussels.

Fox, M., 2005. Gender, Family Characteristics, and Publication Productivity among Scientists. Social Studies of Science, 35 (1), 131-150.

Frank, S., 2006. R\&D-Personnel. Statistics in Focus, 7/2006. Eurostat, Brussels.

Freeman, C., 1982. The Economics of Industrial Innovation. Pinter, London. 
Frietsch, R., Schmoch, U., 2006. Technological Structures and Performance Reflected by Patent Indicators. In Schmoch, U., Rammer, C., Legler, H. (Eds.). National Systems of Innovation in Comparison. Structure and Performance Indicators for Knowledge Societies. Springer, Dordrecht.

Grupp, H., 1998. Foundations of the Economics of Innovation. Cheltenham: Edward Elgar.

Holz, G., 2003. Kinderarmut verschärft Bildungsmisere. Aus Politik und Zeitgeschichte. B21-22, 3-5.

Kash, D. E., Kingston, W., 2001. Patents in a world of complex technologies, Science and Public Policy, 28, 11-22.

Leahey, E., 2006. Gender differences in productivity - Research specialization as a missing link. Gender \& Society, 20 (6), 754-780.

Long, J.S., 1990. The Origins of Sex Differences in Science. Social Forces, 68 (4), 1297-1315.

Long, J.S., 1992. Measures of Sex Differences in Scientific Productivity. Social Forces, 71 (1), 159-178.

Long, J. S. 2001. From Scarcity to Visibility: Gender Differences in the Careers of Doctoral Scientists and Engineers. Washington, DC: National Academy Press.

Machin, S., Puhani, P.A., 2003. Subject of degree and the gender wage differential: evidence from the UK and Germany. Economics Letters, 79 (3), 393-400.

Mauleón, E., Bordons, M., 2006. Productivity, impact and publication habits by gender in the area of Materials Science. Scientometrics, 66 (1), 199-218.

Moed, H.F., Glänzel, W., Schmoch, U. (Eds.), 2004. Handbook of Quantitative Science and Technology Research. The Use of Publications and Patent Statistics in Studies of S\&T Systems. Kluwer Academic Publisher, Dordrecht.

Moody, J., 2004. The structure of a Social Science Collaboration Network: Disciplinary Cohesion from 1963 to 1999. American Sociological Review, 69, 213-238.

Moody, J., Light R., 2006. A view from above: The evolving sociological landscape. The American Sociologist, 37 (2), 67-86.

Naldi, F., Vannini Parenti, I., 2002a. Scientific and Technological Performance by Gender, Vol 1, European Commission.

Naldi, F., Vannini Parenti, I., 2002b. Scientific and Technological Performance by Gender, Vol 2, European Commission. 
OECD Employment, 2006. Women in Scientific Careers: Unleashing the Potential, Vol. 2006, Number 9, November 2006 , i-209.

Penas, C.S., Willett, P., 2006. Gender differences in publication and citation counts in librarianship and information science research. Journal of Information Science, 32 (5), 480-485.

Prpic, K., 2002. Gender and productivity differentials in science. Scientometrics, 55 (1), 27-58.

Schmoch, U., Hinze, S., 2004. Opening the Black Box. In Moed, H.F., Glänzel, W., Schmoch, U. (Eds.), Handbook of Qualitative Science and Technology Research. The Use of Publication and Patent Statistics in Studies of S\&T Systems. Kluwer Academic Publishers, Dordrecht, pp. 215-235.

Stack, S., 2004. Gender, children and research productivity. Research in Higher Education, 45 (8), 891-920.

Van Raan, A. (Eds.), 1988. Handbook of quantitative studies of science and technology, Amsterdam.

Viitanen, T. K., 2005. Cost of Childcare and Female Employment in the UK, Labour, 19 (Special Issue) 149-170.

Wirth, H., Dümmler, K., 2005. The Influence of Qualification on Women's Childlessness in West Germany: Age and Cohort Effects, Analyses with the German Microcensus (Rep. No. ZUMA-Arbeitsbericht 2005/3), Mannheim.

Xie, Y., Shauman, K. A., 1998. Sex Differences in Research Productivity: New Evidence about an Old Puzzle. American Sociological Review, 63 (6), 847-870.

Xie, Y., Shauman, K. A., 2003. Women in Science: Career Processes and Outcomes. Cambridge, MA: Harvard University Press.

Zuckerman, H., Cole, J.R., 1975. Women in American Science. Minerva, 13 (1), 82102. 


\section{$8 \quad$ Web-References}

Commission of the European Communities, 2003. Communication from the Commission to the Council and the European Parliament. URL:

http://cordis.europa.eu/documents/documentlibrary/2063EN.pdf (accessed 14.12.2007).

Elsevier: http://www.scopus.com/scopus/home. URL (19.04.2007)

European Commission, 2006a. Report on equality between women and men, 2006.

URL: http://ec.europa.eu/employment_social/publications/2006/keaj06001_en.pdf (05.12.2007).

European Commission, 2006b. Women and Science. Statistics and Indicators. European Commission, 2006. URL: http://ec.europa.eu/research/sciencesociety/pdf/she_figures_2006_en.pdf (16.11.2007).

European Commission, 2007. Remuneration of Researchers in the Public and Private Sectors, European Commission, 2007. URL:

http://ec.europa.eu/eracareers/pdf/final_report.pdf (13.12.2007).

European Union: Gender Equality:

http://ec.europa.eu/employment_social/gender_equality/index_en.html (02.02.2006).

Eurostat, 2006. 8. März 2006: Internationaler Frauentag, Das Leben der Frauen und Männer in der EU25 aus Sicht der Statistik, Pressemitteilung. URL:

http://epp.eurostat.cec.eu.int/pls/portal/docs/PAGE/PGP_PRD_CAT_PREREL/P GE_CAT_PREREL_YEAR_2006/PGE_CAT_PREREL_YEAR_2006_MONTH_03 /3-06032006-DE-BP1.PDF (13.12.2007).

Thomson: http://scientific.thomson.com/free/essays/journalcitationreports/impactfactor/ (30.04.2007).

United States Government Accountability Office 2005: Higher Education: Federal Science, Technology, Engineering, and Mathematics Programs and Related Trends. GAO-06-114, October 12. URL: http://www.gao.gov/cgi-bin/getrpt? GAO-06-114 (18.12.2007). 